\title{
Considerações sobre os desafios jurídicos do uso da Inteligência Artificial na medicina
}

\author{
Considerations on the legal challenges of the use of Artificial Intelligence in medicine
}

\author{
Denise Oliveira dos Santos* \\ Luciana Berbigier Lucas**
}

\section{REFERÊNCIA}

SANTOS, Denise; LUCAS, Luciana. Considerações sobre os desafios jurídicos do uso da Inteligência Artificial na medicina. Revista da Faculdade de Direito da UFRGS, Porto Alegre, n. 46, p. 71-92, ago. 2021. DOI: https://doi.org/10.22456/0104-6594.107624.

\section{RESUMO}

O uso da Inteligência Artificial na medicina possibilita que uma quantidade grande de dados seja analisada com altos índices de precisão e em um curto espaço de tempo. Todavia, por se tratar de uma tecnologia sem precedentes e que evolui em uma proporção imensurável a cada dia, a Ciência do Direito se vê impelida a se adaptar para que possa lidar com a demanda jurídica decorrente dessa nova realidade. Como forma de auxiliar a pesquisa jurídica a refletir sobre o assunto, o presente trabalho se propõe a analisar aspectos relevantes sobre o estudo da responsabilização pelos atos de Inteligência Artificial, especialmente os relacionados à medicina. A primeira parte identifica as principais características das tecnologias que operam através do uso da Inteligência Artificial. A segunda, apresenta reflexões sobre o tema especificamente na área médica e, por fim, a terceira parte analisa a responsabilização pelos eventuais danos causados pelas máquinas que operam utilizando a Inteligência Artificial. Foi utilizado o método de pesquisa de revisão bibliográfica. Verificou-se que a utilização de Inteligência Artificial, em especial na área médica, envolve riscos que devem ser cuidadosamente ponderados em face dos benefícios que possa proporcionar, sobretudo diante da insegurança e incerteza jurídica que a temática apresenta já que, no Brasil, até o presente momento, inexiste legislação específica sobre o tema da responsabilização por atos autônomos de sistemas de Inteligência Artificial.

\section{PALAVRAS-CHAVE}

Inteligência Artificial. Responsabilidade Legal. Medicina.

\begin{abstract}
The use of Artificial Intelligence in medicine enables vast quantities of data to be processed in a short time and high levels of accuracy. However, since it is an emerging technology which evolves in an unmeasurable proportion every day, the Science of Law is compelled to adapt itself in order to deal with legal demands arising from this modern reality. This article aims to review relevant aspects of the study of accountability for Artificial Intelligence actions, in particular those related to medicine, as a way to assist legal analysis to ponder the subject. The first section describes the key characteristics of the systems that use Artificial Intelligence to perform. The second section provides perspectives on the subject primarily in the medical field, and finally the third section analyzes the responsibility for any harm incurred by the devices that use Artificial Intelligence to operate. The bibliographic review search method was applied. It was found that the use of Artificial Intelligence, particularly in the medical context, implies risks that need to be carefully weighed in view of the benefits that could be experienced, particularly due to the instability and legal uncertainty that the theme raises, mainly because there is no relevant legislation in Brazil until now on the topic of accountability for Artificial Intelligence autonomous actions.
\end{abstract}

\section{KEYWORDS}

Artificial Intelligence. Legal Liability. Medicine.

\section{SUMÁRIO}

* Mestre em Direito pela Universidade Federal do Rio Grande do Sul (UFRGS).

** Advogada Pública. Doutoranda em Direito pela PUCRS. Mestre em Direito pela PUCRS. 
1. Introdução. 2. Noções gerais sobre inteligência artificial. 3. Inteligência artificial na área médica. 4. Responsabilização pelos atos autônomos de inteligência artificial. 5. Conclusão. Referências. Dados da publicação.

\section{INTRODUÇÃO}

A interação com robôs e computadores no nosso dia a dia já não está limitada a figurar como premissa de filmes de ficção científica, mas é algo que está presente na rotina das pessoas. Sofisticados sistemas operando através de algoritmos dotados de Inteligência Artificial (IA) movimentam a economia global em diversas áreas como agricultura, indústria, aviação, comércio e mercado financeiro. A IA potencializa também a capacidade de outros mercados como o de segurança, operando a sistemas de câmeras de vigilância que utilizam o reconhecimento facial para identificar pessoas e movimentos suspeitos, assim como bloquear ou dar acesso a uma residência, por exemplo.

A busca por métodos e dispositivos capazes de simular a cognição e o raciocínio humano vem sendo objeto de estudo e tem como um de seus objetivos fornecer às máquinas a possibilidade de desenvolver habilidades que até então somente o cérebro humano seria capaz de apresentar. Com o progresso de novas tecnologias da informação e a aplicação da IA nas mais diversas áreas do conhecimento, tarefas complexas são solucionadas em um espaço de tempo cada vez menor.

Em paralelo ao movimento de implementação de dispositivos inteligentes no cotidiano, há o aprimoramento dos sistemas, permitindo o aperfeiçoamento na capacidade de coleta, armazenamento e processamento de dados, com a consequente facilitação da sua análise. Assim, acessando um acervo de informações e através de um exame inteligente, robôs ou programas de computador são capazes de resolver problemas em tempo recorde. Graças a avançados métodos de aprendizado de máquinas, quanto mais dados estiverem acessíveis, maior será a aptidão de modificar seu próprio funcionamento a partir da associação de experiências acumuladas em ações e atividades executadas anteriormente através da atuação dos algoritmos.

Diante dessa nova realidade, o Direito precisa se adaptar para que esteja apto a resolver problemas decorrentes da interação entre seres humanos e máquinas. Dentre outras, tal adequação na ordem jurídica implica em responder à seguinte questão: como responsabilizar as ações autônomas decorrentes de um sistema que opera através da Inteligência Artificial? É um 
tema que precisa ser enfrentado, especialmente quando aplicado a atos que geram consequências na área médica. Trata-se de uma análise de relevância acadêmica e social, na medida em que está relacionada a direitos fundamentais como saúde e acesso igualitário ao desenvolvimento científico e tecnológico. Também, porque o fato de inexistir uma legislação específica relativa à matéria pode gerar controvérsia e insegurança nas relações interpessoais e jurídicas.

O método de pesquisa escolhido para abordar o tema da responsabilização de atos autônomos de IA, em particular na área médica, foi o da revisão bibliográfica. A análise do problema de pesquisa foi dividida em três tópicos: o primeiro identifica noções gerais sobre IA e suas aplicações, o segundo se dedica à análise específica do tema na área médica e, por fim, o terceiro tópico aborda possíveis formas de responsabilização pelos atos autônomos de máquinas operando através da IA.

\section{NOÇÕES GERAIS SOBRE INTELIGÊNCIA ARTIFICIAL}

Historicamente, a Inteligência Artificial (IA) passou a ser um assunto mais difundido em decorrência dos estudos do cientista da computação Alan Turing, que desenvolveu, em 1950, um teste para tentar definir o grau de inteligência de um computador. No Teste de Turing, um computador seria interrogado por um ser humano através de um terminal; o computador passaria no teste se o inquiridor não fosse capaz de dizer se do outro lado quem respondia às questões era um computador ou um ser humano. A partir de então foram desenvolvidas inúmeras funções, objetivos e aplicações para a matéria, estimulando a progressão dos estudos sobre IA. ${ }^{1}$

Como conceito, a IA é o ramo da ciência da computação que usa algoritmos definidos por especialistas para, através deles, reconhecer uma tarefa a ser realizada, analisar a base de dados e tomar decisões, reproduzindo a capacidade cognitiva humana de pensar e resolver problemas. Logo, a IA constitui um sistema inteligente de computação capaz de realizar tarefas sem receber instruções diretas de humanos. ${ }^{2}$

\footnotetext{
${ }^{1}$ MONARD, Maria Carolina; BARANAUSKAS, José Augusto. Aplicações de inteligência artificial: uma visão geral. In: CONGRESSO DE LÓGICA APLICADA À TECNOLOGIA (LAPTEC), 1., 2000, São Paulo. Anais... São Paulo: USP, 2000. Disponível em: http://dcm.ffclrp.usp.br/ augusto/publications/2000-laptec.pdf. Acesso em: 13 ago. 2020.

${ }^{2}$ LOBO, Luiz Carlos. Inteligência artificial, o futuro da medicina e a educação médica. Revista Brasileira de Educação Médica, Brasília, v. 42, n. 3, p. 3-8, set. 2018. Disponível em:
} 
Como tecnologia, IA pode ser definida como "qualquer sistema baseado em tecnologia da informação que, combinando matemática (algoritmos e outros métodos) e técnicas da ciência da computação, é capaz de fazer com que máquinas se comportem como se fossem inteligentes". ${ }^{3}$

Trata-se de matéria multidisciplinar, pois se relaciona com psicologia, biologia, lógica, matemática, linguística, engenharia, filosofia, ciência da computação, entre outras áreas científicas. Além disso, o estudo da IA se desenvolve em diferentes linhas de pesquisa como por exemplo Robótica, Aprendizado de Máquina, Processamento e Interpretação de Linguagem Natural e Reconhecimento de Padrões, com o objetivo de fornecer ao computador habilidades para executar funções antes desempenhadas apenas através da inteligência humana. ${ }^{4}$

Atualmente, a aplicação da IA no cotidiano é possível em razão da atuação dos algoritmos, que servem para mapear padrões de comportamento em situações determinadas. Um algoritmo é, assim, uma sequência de ações executáveis para mapear e solucionar um determinado tipo de problema; é uma descrição de um padrão de comportamento, expresso em termos de um conjunto finito de ações. ${ }^{5}$

O processamento de informações pela mente humana com suas ideias, conceitos e conhecimentos é o objeto de estudo da Ciência Cognitiva, outra área da ciência que está diretamente relacionada ao processamento de informações pela IA quando associa padrões de comportamento e aprende com eles. O processo cognitivo humano "envolve atividades mentais como o pensamento, a imaginação, a recordação, a solução de problemas, a percepção, o julgamento, a aprendizagem da linguagem, entre outras as quais ocorrem diferentemente em cada indivíduo, dependendo do grau de habilidade de cada um"6. A capacidade de cognição, por sua vez, está intrinsecamente ligada à Ciência da Informação pois cada ato de

http://www.scielo.br/scielo.php?script=sci_arttext\&pid=S0100-55022018000300003\&lng=en\&nrm=iso. Acesso em: 13 abr. 2020.

${ }^{3}$ SOUZA, Cesar Alexandre de. PAULI, Sergi. A nova era da inteligência artificial e o futuro do trabalho. Revista Fonte: Tecnologia da Informação na Gestão Pública, Minas Gerais, Ano 14, n. 17, p. 77-83, Jul. 2017. Disponível em: https://www.prodemge.gov.br/revista-fonte/Publication/19-Computacao-cognitiva-e-a-humanizacao-dasmaquinas. Acesso em: 04 ago. 2020, p. 79.

${ }^{4}$ MONARD, Maria Carolina; BARANAUSKAS, José Augusto. Aplicações de inteligência artificial: uma visão geral. In: CONGRESSO DE LÓGICA APLICADA À TECNOLOGIA (LAPTEC), 1., 2000, São Paulo. Anais... São Paulo: USP, 2000. Disponível em: http://dcm.ffclrp.usp.br/ augusto/publications/2000-laptec.pdf. Acesso em: 13 ago. 2020.

${ }^{5}$ ZIVIANI, Nivio. Projeto de Algoritmos com Implementações em Pascal e C. São Paulo: Pioneira, 1999 , p. 1.

${ }^{6}$ LIMA, Gercina Ângela Borém. Interfaces entre a ciência da informação e a ciência cognitiva. Ciência da Informação, Brasília, v. 32, n. 1, p. 77-87, jan./abr. 2003. Disponível em: <https://www.scielo.br/scielo.php?script=sci_arttext\&pid=S0100-19652003000100008\&lng=en\&nrm=iso>. Acesso em: 04 ago. 2020. 
processamento da informação cria um modelo de mundo, mediado por um sistema de categorias e conceitos. Desta forma, o reconhecimento das similaridades e diferenças no processo de categorização, leva à criação de um conhecimento novo. ${ }^{7}$

Os conceitos de cognição e categorização da informação aplicáveis para os seres humanos auxiliam para o entendimento sobre como funcionam os algoritmos de IA e a simulação do processo do pensamento humano de uma forma computadorizada. Neste sentido, Ziviani ${ }^{8}$ esclarece que:

O propósito da inteligência artificial é desenvolver software para automatizar trabalho rotineiro, entender a fala ou descrever os componentes de imagens, realizar diagnósticos em medicina e dar suporte à pesquisa científica básica. $\mathrm{O}$ grande desafio para a inteligência artificial provou ser a solução de tarefas intuitivas que são fáceis de serem realizadas pelos seres humanos, mas difíceis para as pessoas descreverem formalmente. A solução desses problemas intuitivos tem evoluído para permitir que os computadores aprendam a partir da experiência e entendam o mundo em termos de uma hierarquia de conceitos, em que cada conceito é definido por meio da sua relação com conceitos mais simples. A partir da hierarquia de conceitos, é possível para o computador aprender conceitos complicados. A subárea da inteligência artificial que tem levado a grandes avanços se chama aprendizado de máquina.

Conforme identificado por Ziviani, uma das formas mais utilizadas para "ensinar a máquina" a ser inteligente é o machine learning - aprendizado de máquina, em tradução livre para o português, comumente referido na bibliografia pela sigla ML. Dentro desse método, a técnica mais difundida é a chamada deep learning - aprendizagem profunda, em tradução livre para o português -, consistindo em "um algoritmo inspirado no processo por meio do qual o cérebro humano funciona" ${ }^{\prime}$, unindo um sistema de redes neurais artificiais que imitam as dos seres humanos a uma quantidade imensa de dados, permitindo maior flexibilidade e a criação de programas de computador que possam "compreender". Pires e Silva ${ }^{10}$ destacam que "Como resultado, tal algoritmo não conhece limitações teóricas sobre o que ele mesmo pode alcançar: quanto mais dados o programa receber, maior será a sua aprendizagem e aptidão para realizar atividades diversas".

\footnotetext{
${ }^{7}$ LIMA, Gercina Ângela Borém. Interfaces entre a ciência da informação e a ciência cognitiva. Ciência da Informação, Brasília, v. 32, n. 1, p. 77-87, jan./abr. 2003. Disponível em: <https://www.scielo.br/scielo.php?script=sci_arttext\&pid=S0100-19652003000100008\&lng=en\&nrm=iso>. Acesso em: 04 ago. 2020.

${ }^{8}$ ZIVIANI, Nivio. Diálogo. Revista Fonte: Tecnologia da Informação na Gestão Pública, Minas Gerais, Ano 14, n. 17, p. 6-12, jul. 2017. Disponível em: https://www.prodemge.gov.br/revista-fonte/Publication/19-Computacaocognitiva-e-a-humanizacao-das-maquinas. Acesso em: 04 ago. 2020. p. 7.

${ }^{9}$ PIRES, Thatiane Cristina Fontão; SILVA, Rafael Peteffi da. A responsabilidade civil pelos atos autônomos da inteligência artificial: notas iniciais sobre a Resolução do Parlamento Europeu. Revista Brasileira de Políticas Públicas, Brasília, v. 7, n. 3, p. 238-254, dez. 2017. Disponível em: https://www.publicacoesacademicas.uniceub.br/RBPP/article/view/4951/3643. Acesso em: 16 abr. 2020. p. 242. ${ }^{10}$ Ibidem.
} 
O desenvolvimento das pesquisas e a criação de modernos métodos e técnicas de processamento de dados, novos softwares e linguagens de programação aumentou exponencialmente o número de dispositivos eletrônicos que funcionam e interagem de maneira similar ao raciocínio humano, fazendo com que atualmente algoritmos e a IA sejam uma realidade no dia a dia das pessoas. Hoje, aplicativos de celular que indicam rotas, como Waze e Google Maps, cruzam informações de diversas fontes para traçar uma média para o tempo do percurso do trajeto definido. Também, uma simples busca na internet é influenciada pelas pesquisas prévias efetuadas no dispositivo, fazendo com que a mesma pesquisa tenha resultados diferentes quando executada em um computador e em um celular.

Os algoritmos de IA se tornam capazes de tomar decisões autonomamente a partir da grande quantidade de informação que lhes é fornecida na sua criação, entretanto uma das questões que pesquisadores enfrentam é se a ciência já é capaz de ensinar aos robôs parâmetros éticos de comportamento. O robô humanoide "Não", responsável por ajudar pessoas a lembrar de tomar uma medicação prescrita por um médico, foi o primeiro a ter o comportamento guiado por princípios éticos, no ano de 2010. Anderson e Anderson ${ }^{11}$ sustentam que é possível ensinar robôs a realizar escolhas éticas, pois, ao analisar a descrição de uma situação específica em muitos contextos em que os robôs provavelmente funcionam, a maioria dos especialistas na área concorda com o que é eticamente admissível e o que não é. Por outro lado, nas situações em que não exista tal acordo, os autores acreditam que as máquinas não devem ter permissão para tomar decisões autônomas.

$\mathrm{Na}$ medida em que a autonomia das máquinas vai crescendo, surgem problemas como o da responsabilização pelos atos autônomos de IA. Isso ocorre porque robô dotado de IA age de maneira independente sem a ingerência do ser humano, mas mais do que isso: tem a capacidade de aprender sozinho com suas experiências anteriores, modificar seu sistema originário e reagir de formas que não foram previamente determinadas pelo desenvolvedor do algoritmo. Assim, as decisões decorrentes do processo de aprendizagem da IA são dotadas de uma característica "autonomia robótica" desde a sua concepção, e esse é um dos principais pontos que dificulta a responsabilização legal de qualquer pessoa física ou jurídica.

A autonomia na ação da IA relevante para o presente estudo não deve ser confundida com as situações em que o programa executa autonomamente métodos de investigação que lhes

\footnotetext{
11 ANDERSON, Michael; ANDERSON, Susan. Robot be good. Scientific American, 2010. Disponível em: https://www.scientificamerican.com/article/robot-be-good/. Acesso em: 20 mai. 2020. p. 75-76.
} 
foram ensinados pelo homem, nem com uma autonomia simulada através da automação ou pela ausência de controle humano simultâneo. O recorte de autonomia relevante para a presente pesquisa é aquele em que o robô ou software dotado de IA possa gerar "sua própria heurística", ou seja, descobrir e aprender fatos novos através de suas próprias experiências. ${ }^{12}$

É necessário refletir sobre a responsabilidade do uso das novas tecnologias, tendo em vista a indiscutível relevância econômica e social da IA nos dias de hoje. Tendo esclarecido o que é, como funciona a IA e como essas características estão relacionadas ao problema de pesquisa, o próximo tópico se dedica a analisar as especificidades da temática na área médica.

\section{INTELIGÊNCIA ARTIFICIAL NA ÁREA MÉDICA}

O uso de softwares e robôs dotados de Inteligência Artificial (IA) nas atividades da medicina transformou de forma permanente práticas médicas como a previsão de cenários clínicos, a determinação de diagnósticos e a realização de cirurgias. Através da IA, as análises médicas se tornaram mais ágeis e mais baratas, otimizando a gestão de recursos humanos, promovendo uma mudança na maneira como trabalhadores na área da saúde, pacientes e sistemas de saúde se relacionam com a tecnologia.

Com rapidez, de maneira intuitiva e inteligente os computadores analisam dados e buscam respostas para os mais diferentes problemas e questionamentos médicos. Dispositivos vestíveis (wearable devices) já estão disponíveis no mercado e são capazes de medir níveis de componentes sanguíneos e injetar substâncias no corpo do paciente (como injeções de insulina, por exemplo). Esse tipo de dispositivo também pode identificar a necessidade de uma descarga elétrica de um desfibrilador subcutâneo e executá-la ou modificar a dose de um medicamento para pacientes com doença de Parkinson. ${ }^{13}$

Em 2020 a ciência e a medicina contam com softwares, IA, drones e robôs para reduzir o impacto negativo de um desafio sem precedentes para a humanidade: a pandemia do Covid19. Dias antes de a Organização Mundial da Saúde emitir oficialmente o primeiro alerta sobre a disseminação do coronavírus, um sistema de IA detectou que o vírus estava se propagando,

\footnotetext{
${ }^{12}$ KARNOW, Curtis E. A. The application of traditional tort theory to embodied machine intelligence. In: CALO, Ryan; FROOMKIN, A. Michael; KERR, Ian. Robot law. Cheltenham, United Kingdom: Edward Elgar Publishing, 2015. Disponível em: https://works.bepress.com/curtis_karnow/9/. Acesso em: 13 ago. 2020.

${ }^{13}$ LOBO, Luiz Carlos. Inteligência artificial, o futuro da medicina e a educação médica. Revista Brasileira de Educação Médica, Brasília, v. 42, n. 3, p. 3-8, set. 2018. Disponível em: http://www.scielo.br/scielo.php?script=sci_arttext\&pid=S0100-55022018000300003\&lng=en\&nrm=iso. Acesso em: 13 abr. 2020.
} 
identificou o epicentro na capital da província de Hubei, na China, previu cidades para as quais a pandemia iria se alastrar (como Seul, Taipei, Tóquio e Bangkok) e emitiu alertas para organizações de saúde. O algoritmo da empresa canadense de tecnologia para a saúde BlueDot cruzou e compilou dados de fontes internacionais em 65 idiomas, rastreou redes de pesquisa em saúde, dados de aeroportos e companhias aéreas, comunicados oficiais de empresas ligadas ao agronegócio e à pecuária, entre outras. ${ }^{14} \mathrm{O}$ pioneirismo na constatação da pandemia também levou os pesquisadores da BlueDot a publicar o primeiro artigo científico identificando o potencial para disseminação internacional do Covid-19. ${ }^{15}$

A Organização Mundial da Saúde (OMS) reconhece que as tecnologias digitais e a IA estão revolucionando os campos da medicina, da pesquisa e da saúde pública em uma abrangência transnacional. Todavia, embora auxilie a manter altos níveis de produtividade e de qualidade com precisão nas análises, a OMS reconhece que a aplicação da IA na rotina médica esbarra em questões éticas, legais e sociais como o acesso equitativo, questões sobre privacidade, uso apropriado da tecnologia e responsabilização sobre todos esses aspectos. ${ }^{16}$

Identificando a relevância mundial das discussões sobre a matéria, a OMS tem atuado de forma interdisciplinar juntamente com outras organizações internacionais como representantes de governos, de agências intergovernamentais, da indústria, da sociedade civil, além de pesquisadores, tecnólogos, advogados, profissionais de saúde, cientistas e especialistas em ética. Representantes de diversos segmentos debatem sobre como os diferentes usos da IA estão transformando campos, tais como a descoberta de medicamentos, a medicina clínica e a saúde pública, bem como estão contribuindo com seus conhecimentos sobre os usos atuais e previstos das tecnologias de IA para a saúde, tecendo diretrizes éticas de governança e princípios de direitos humanos que devem orientar o desenho e implementação da IA na saúde global. $^{17}$

Pesquisadores acreditam que a manipulação de dados (big data) por sistemas inteligentes operando por intermédio do deep learning, juntamente com o desenvolvimento da computação e do sistema de armazenamento em nuvem, impactam positivamente a medicina em três níveis: os médicos, predominantemente através da interpretação rápida e precisa da

\footnotetext{
14 DEMARTINI, Felipe. Inteligência artificial emitiu aviso sobre coronavírus em dezembro. Canaltech. Disponível em: https://canaltech.com.br/saude/inteligencia-artificial-emitiu-aviso-sobre-coronavirus-emdezembro-159607/. Acesso em: 06 ago. 2020.

${ }^{15}$ BLUEDOT. Our leadership on COVID-19. Disponível em: https://bluedot.global. Acesso em: 06 ago. 2020.

${ }^{16}$ WHO. World Health Organization. Global health ethics: big data and artificial intelligence. Disponível em: https://www.who.int/ethics/topics/big-data-artificial-intelligence/en/. Acesso em: 12 mai. 2020.

${ }^{17}$ Ibidem.
} 
imagem; os sistemas de saúde, melhorando o fluxo de trabalho e ocasionando uma potencial redução de erros médicos; e os pacientes, que passam a ter acesso a seus dados, podendo cuidar da própria saúde. Dentre as limitações dessa realidade estão a privacidade e segurança dos dados gerados, a transparência e a incerteza do que o futuro reserva para esse cenário. ${ }^{18}$

Os dados sobre a saúde de uma pessoa incluem, entre outras, informações sobre o estilo de vida, histórico de consultas médicas, exames laboratoriais e de imagem, diagnósticos, medicamentos prescritos e procedimentos cirúrgicos realizados. $\mathrm{O}$ acesso aos dados adequados e por intermédio do uso da IA tem o potencial de melhorar a qualidade dos cuidados às pessoas, reduzir custos e até detectar doenças em estágios iniciais, quando comparado a métodos tradicionais de análise de dados de saúde. Estudiosos afirmam que a capacidade de estratificar os pacientes, desvendar cenários e otimizar a tomada de decisões melhoraria consistentemente caso tivesse acesso a dados obtidos durante o processo de prestação de cuidados médicos. Todavia, para que a integração e análise de informações de saúde opere com um nível aceitável de segurança, é preciso superar desafios como o tratamento que seria dado à privacidade dos dados, a existência de múltiplos padrões de registro dos dados, a variação na estrutura dos sistemas operacionais, assim como os diferentes tipos e formatos de informação e abordagens. ${ }^{19}$

Para que seja possível colher os benefícios do deep learning é imprescindível acessar grandes conjuntos de dados (big data), com os quais as redes neurais de IA possam construir e evoluir o seu aprendizado. Para tanto, uma parte da doutrina defende a necessidade de abertura de grandes bases de dados de prontuários médicos que hoje são exclusivas ou privadas. Salathé ${ }^{20}$ ressalta que a maioria dos algoritmos subjacentes ao deep learning está disponível de forma aberta e gratuita, mas que a privacidade e a restrição ao acesso a conjuntos de dados está se tornando o fator limitante no desenvolvimento da IA. O autor defende a tese de que é do interesse público garantir que o máximo de dados possível seja abertamente acessível, embora reconheça que esse interesse coletivo está claramente em desacordo com o desejo compreensível da maioria das pessoas de ter o mínimo possível de dados pessoais de livre acesso para proteger sua privacidade. Assim, surge a questão sobre como seria resolvido o

\footnotetext{
${ }^{18}$ TOPOL, Eric J. High-performance medicine: the convergence of human and artificial intelligence. Nature Medicine, China, v. 25, p. 44-56, jan. 2019. DOI: https://doi.org/10.1038/s41591-018-0300-7.

${ }^{19}$ AHMED, Zeeshan et al. Artificial intelligence with multi-functional machine learning platform development for better healthcare and precision medicine. Database: The journal of Biological Database and Curation, Oxford, v. 2020, p. 1-35, 2020. Disponível em:

https://academic.oup.com/database/article/doi/10.1093/database/baaa010/5809229. Acesso em: 05 mai. 2020.

${ }^{20}$ SALATHÉ, Marcel. Digital epidemiology: what is it, and where is it going? Life Sciences, Society and Policy, New York, v. 14, n. 1, p. 1-5, 2018. Diponível em: https://sspjournal.biomedcentral.com/articles/10.1186/s40504017-0065-7. Acesso em: 12 mai. 2020.
} 
impasse gerado por um conflito de interesses "coletivo versus individual". Soluções possíveis sugeridas pelo autor seriam a criação de cooperativas de dados com acesso restrito e a evolução de métodos de criptografia de dados.

Pode se afirmar, portanto, que o desenvolvimento da IA será tão avançado quanto as informações que the servem como fonte de conhecimento pois "a qualidade da decisão automatizada (output), baseada em um algoritmo, tem uma correlação direta com a qualidade dos dados que ele processa (input)". ${ }^{21}$ Logo, se o algoritmo se baseia em dados históricos repletos de preconceitos, ele reproduzirá, de forma automatizada, padrões preconceituosos. $\mathrm{Na}$ área médica, por lidar com situações de vida ou morte, é ainda mais necessário buscar a padronização dos dados, bem como, assegurar que sejam fidedignos. ${ }^{22}$

Neste ponto, vale salientar que, no Brasil, a Lei n. 13.709 de 2018 trata sobre a proteção de dados e permite o acesso aos órgãos de pesquisa a bases de dados pessoais na realização de estudos em saúde pública, desde que os dados sejam tratados exclusivamente dentro do órgão e estritamente para a finalidade de realização de estudos e pesquisas, mantidos em ambiente controlado e seguro, conforme práticas de segurança previstas em regulamento específico e que incluam, sempre que possível, a anonimização ou pseudonimização dos dados, bem como considerem os devidos padrões éticos relacionados a estudos e pesquisas. ${ }^{23}$

De outra parte, a Lei n. 12.842 de 2013 dispõe sobre o exercício da medicina e veda a realização de qualquer ato médico, inclusive de diagnóstico, sem a participação de um profissional devidamente habilitado por se tratar de atividade privativa do graduado em curso superior de medicina. ${ }^{24}$ Neste sentido, o Conselho Federal de Medicina emitiu parecer contrário à utilização de um robô para testes de acuidade visual, sem a supervisão de um médico oftalmologista. $^{25}$

Portanto, embora a IA não possa substituir os médicos, há evidências de que possa auxiliar de forma efetiva a análise de dados médicos. Ao aplicar o deep learning a prontuários de 700.000 pacientes de um hospital em Nova Iorque no ano de 2015, pesquisadores se

\footnotetext{
${ }^{21}$ DONEDA, Danielo Cesar et al. Considerações iniciais sobre inteligência artificial, ética e autonomia pessoal. Revista de Ciências Jurídicas, Fortaleza, v. 23, n. 4, p. 1-17, out./dez. 2018. Disponível em: https://periodicos.unifor.br/rpen/article/view/8257. Acesso em: 02 set. 2019, p. 5.

22 Ibidem.

${ }^{23}$ BRASIL. Lei $n$. 13.709, de 14 de agosto de 2018. Disponível em: http://www.planalto.gov.br/ccivil_03/_ato2015-2018/2018/lei/L13709.htm. Acesso em: 12 mai. 2020.

${ }^{24}$ BRASIL. Lei $n$. 12.842, de 10 de julho de 2013. Disponível em: http://www.planalto.gov.br/ccivil_03/_ato20112014/2013/lei/l12842.htm. Acesso em: 12 maio 2020.

25 CFM. Conselho Federal de Medicina. Despacho CFM n. 319/2019. Disponível em: https://sistemas.cfm.org.br/normas/visualizar/despachos/BR/2019/319. Acesso em: 12 mai. 2020.
} 
surpreenderam com o potencial do software denominado Deep Patient em prever doenças como câncer e esquizofrenia ao descobrir e analisar padrões "ocultos" nos prontuários. Entretanto, os desenvolvedores reconhecem que não saberiam mapear as razões pelas quais o sistema foi capaz de apresentar esses resultados, fazendo com que seja levantada a questão sobre o quão compreensível ou explicável a IA pode ser. ${ }^{26}$

Estudos sobre a explicabilidade dos modelos que utilizam o machine learning em contextos médicos sugerem que deve haver espaço para discordâncias acerca das decisões e resultados apresentados por mecanismos dotados de IA. Assim, os caminhos utilizados pelos modelos devem ser explicáveis a ponto de permitir que o tomador da decisão final adote uma postura crítica em relação às recomendações do modelo, permitindo que os médicos tenham condições de verificar os motivos de um resultado específico. Antes disso, como um prérequisito legal para justificar a implementação desses modelos, os autores sugerem testes de validação de critérios de adequação clínica que avaliem se o modelo apresenta evidências empíricas de vantagens clínicas. ${ }^{27}$

A Resolução europeia 2015/2103 (INL), ao tratar especificamente sobre o uso dos robôs na medicina considera que, em caso algum, a utilização da robótica, de instrumentos de diagnóstico ou de tratamento de alta tecnologia deverá resultar num aumento da responsabilidade dos médicos ou profissionais de saúde que se vejam obrigados a utilizá-los. Por conseguinte, considera aconselhável aumentar a responsabilidade dos estabelecimentos de prestação de cuidados de saúde ou dos fabricantes envolvidos. ${ }^{28}$

Dentre os riscos e desafios da IA, temos como aspectos negativos a redução do controle humano, já que a IA facilita a delegação de tarefas; a tendência remoção de responsabilidade humana e transferência da atribuição da responsabilidade sempre que possível do sistema de IA, devido à complexa rede de fornecedores, desenvolvedores e designers envolvidos no processo de criação; a desvalorização das competências humanas "nomeadamente em domínios

\footnotetext{
${ }^{26}$ KNIGHT, Will. The dark secret at the heart of AI: no one really knows how the most advanced algorithms do what they do - that could be a problem. 2017. Technology Review. Disponível em: https://www.technologyreview.com/2017/04/11/5113/the-dark-secret-at-the-heart-of-ai/. Acesso em: 29 abr. 2020.

${ }^{27}$ HACKER, P. et al. Explainable AI under contract and tort law: legal incentives and technical challenges. Artificial Intelligence and Law, Berlin, v. 28, p. 415-439, 2020. Disponível em: https://link.springer.com/article/10.1007/s10506-020-09260-6. Acesso em: 27 abr. 2020.

${ }^{28}$ UNIÃO EUROPEIA. Resolução 2015/2103 (INL), de 16 de fevereiro de 2017. Contém recomendações à Comissão sobre disposições de Direito Civil sobre Robótica. Disponível em: https://www.europarl.europa.eu/doceo/document/A-8-2017-0005_PT.html\#title2. Acesso em: 29 abr. 2020.
} 
sensíveis e intensivos, como o diagnóstico médico e a aviação", visto que pode desencadear a escassez de especialistas humanos capazes de diagnosticar. ${ }^{29}$

Diante deste contexto, abordaremos abaixo as formas de responsabilização legal pelos atos dos sistemas de IA que causarem danos aos seus usuários ou a terceiros.

\section{RESPONSABILIZAÇÃO PELOS ATOS AUTÔNOMOS DE INTELIGÊNCIA ARTIFICIAL}

Como já referido os sistemas de computação, mediante o uso da tecnologia de Inteligência Artificial (IA), têm a capacidade de atuar de forma totalmente autônoma, de modo que "deixam o status de ferramenta e passam a desempenhar ações independentes de uma direção ou instrução específica determinada por um ser humano". ${ }^{30}$ Em outras palavras, os sistemas dotados de IA têm como base para a tomada de decisões informações que eles absorvem através de suas próprias experiências anteriores. O problema é que, muitas vezes, essas atitudes autônomas poderão ensejar consequências danosas, em circunstâncias que não necessariamente foram premeditadas por seus criadores. ${ }^{31}$

Ao refletir sobre atos praticados por robôs dotados de IA e como seria a responsabilização destas ações - pois elas podem gerar consequências que precisarão ser analisadas e responsabilizadas em diferentes dimensões jurídicas como civil, penal e consumidor - esbarra-se na falta de um enquadramento legal e de diretrizes para o uso desse tipo de inovação.

Viver em comunidade naturalmente demanda que existam formas de organização da convivência. De maneira geral, historicamente, essa organização foi buscada através da tutela do Direito e sua ordem jurídica, estabelecida através de leis e códigos que regulam a vida em sociedade. Assim, da necessidade de vincular os destinatários do Direito e as leis, deriva o instituto da personalidade jurídica, que torna pessoas físicas e pessoas jurídicas titulares de direitos e obrigações. Todos esses institutos funcionaram até hoje para tratar de relações entre

\footnotetext{
${ }^{29}$ DONEDA, Danielo Cesar et al. Considerações iniciais sobre inteligência artificial, ética e autonomia pessoal. Revista de Ciências Jurídicas, Fortaleza, v. 23, n. 4, p. 1-17, out./dez. 2018. Disponível em: https://periodicos.unifor.br/rpen/article/view/8257. Acesso em: 02 set. 2019. p. 11-12.

${ }^{30}$ PIRES, Thatiane Cristina Fontão. SILVA, Rafael Peteffi da. A responsabilidade civil pelos atos autônomos da inteligência artificial: notas iniciais sobre a Resolução do Parlamento Europeu. Revista Brasileira de Políticas Públicas. v. 7, n. 3, Dez. 2017. Disponível em: https://www.publicacoesacademicas.uniceub.br/RBPP/article/view/4951/3643. Acesso em 16 abr. 2020. p. 240. ${ }^{31}$ Ibidem
} 
humanos, todavia, atualmente, vemos a necessidade de regular também a relação entre humanos e robôs.

Em momentos como o que estamos vivendo, em que se consolida a inserção de costumes que mudam de forma drástica as relações interpessoais, nos deparamos com a necessidade da adaptação das leis para que a estabilidade das relações jurídicas continue sendo assegurada, mantendo a segurança jurídica. Assim, diante da inerência da IA no cotidiano, a Ciência do Direito se vê compelida a também se adaptar. Dentre as principais discussões sobre o tema está o questionamento sobre como responsabilizar as ações de um robô operando autonomamente através da IA.

No caso específico dos atos autônomos da IA, as opiniões se dividem sobre a necessidade de atribuição ou não de algum tipo de personalidade ou registro especial para que seja possível a responsabilização e a obrigação de reparar danos causados.

Sobre o ponto, vale lembrar que divindades, animais, plantas e até mesmo a alma já foram reconhecidos em períodos históricos remotos como titulares de direitos, mesmo sem ter uma personalidade jurídica reconhecida para fins de imputação de responsabilidade. ${ }^{32}$ No passado, escravos não eram reconhecidos como pessoas com direitos, mas a eles eram atribuídas responsabilidades e estavam sujeitos a graves punições. Outro exemplo interessante é a situação jurídica dos animais: embora não possuam um registro civil, são destinatários de direitos perante a legislação brasileira. Ademais, na figura da pessoa jurídica, Estados e empresas são reconhecidos como sujeitos destinatários de direitos e estão submetidos a leis que estabelecem responsabilidades pelos seus atos, embora não sejam seres dotados de vida no sentido biológico e orgânico.

Em uma perspectiva conservadora sobre o tema, Asaro ${ }^{33}$ faz uma analogia entre o tratamento que os animais domésticos recebem na lei e os robôs, explicando que não seria necessário atribuir às máquinas e robôs nenhum direito especial, pois a única preocupação seria em relação aos seus "proprietários". O autor ilustra seu ponto de vista afirmando que claramente os animais possuem alguma capacidade de ação autônoma, no entanto, a eles não são atribuídas responsabilidade moral ou os mesmos direitos e deveres que concedemos a uma pessoa humana.

\footnotetext{
${ }^{32}$ FERREIRA, Ana Elisabete. Responsabilidade civil extracontratual por danos causados por robôs autónomos: breves reflexões. Revista Portuguesa do Dano Corporal, Coimbra, v. 27. Ano 25, p. 39-63, dez. 2016. DOI: https://doi.org/10.14195/1647-8630_27_3.p. 44.

${ }^{33}$ ASARO, Peter M. A Body to kick, but still no soul to damn: legal perspectives on Robotics. In: LIN, Patrick; ABNEY, Keith; BEKEY, George A. Robot Ethics: the ethical and social implications of Robotics. Massachusetts: The MIT Press, 2012. p. 169-187.
} 
Seguindo seu raciocínio, o autor explica que os animais domésticos não são considerados genuinamente perigosos, entretanto, caso causem algum dano a terceiros, seus proprietários serão os responsáveis por responder perante a lei. Ainda, caso seja comprovado que o proprietário tenha agido com comportamento negligente ou mal-intencionado, este poderá pessoalmente responder civil e criminalmente pelas ações de seu animal.

Para o autor, o mesmo padrão poderia ser transportado para resolver problemas decorrentes de atos de robôs, mas ressalta que a análise precisa ser cautelosa: robôs mais comuns seriam considerados como animais domésticos, já um robô experimental poderia ser visto como um animal selvagem, que tende a agir de maneira perigosa ou inesperada. Assim, a pessoa que desenvolve ou utiliza um robô experimental estaria assumindo um risco maior e, consequentemente, uma maior responsabilidade. $\mathrm{O}$ autor defende ainda que a posse e o uso dos robôs sejam restritos a pessoas devidamente treinadas para manipular essa tecnologia, o que estabelece uma conexão explícita e rastreável entre uma parte da tecnologia e um indivíduo responsável - assim como o uso de um avião ou automóvel exige que a pessoa passe por um treinamento e seja aprovada em testes para então obter uma licença específica para operar essas máquinas. $^{34}$

Há também os que questionam se o dever de reparação deveria recair para o fabricante, para a pessoa - física ou jurídica - que adquiriu e utiliza a IA na sua atividade ou, até mesmo, pela pessoa que se beneficia da ação da IA.

Pires e Silva ${ }^{35}$ identificam na literatura estrangeira diferentes maneiras de enquadrar a responsabilização por atos de IA juridicamente, quais sejam: IA como ferramenta e a responsabilidade indireta do usuário ou proprietário; IA como produto e a responsabilidade dos fabricantes; e IA como risco criado e a responsabilidade objetiva daquele a quem o risco aproveita (deep-pocket) ou pela abordagem da gestão de riscos. Na visão dos autores, não importa a forma do enquadramento, mas o certo é que a responsabilidade deverá ser imputada a um ser humano, não a um robô.

O Parlamento Europeu publicou em 2017 a Resolução europeia 2015/2103(INL), com recomendações à Comissão sobre disposições de Direito Civil sobre Robótica, redigida sob o

\footnotetext{
${ }^{34}$ Ibidem, p. 177.

${ }^{35}$ PIRES, Thatiane Cristina Fontão; SILVA, Rafael Peteffi da. A responsabilidade civil pelos atos autônomos da inteligência artificial: notas iniciais sobre a Resolução do Parlamento Europeu. Revista Brasileira de Políticas Públicas, Brasília, v. 7, n. 3, p. 238-254, dez. 2017. Disponível em: https://www.publicacoesacademicas.uniceub.br/RBPP/article/view/4951/3643. Acesso em: 16 abr. 2020. p. 246249.
} 
consenso dos autores de que robôs e formas de IA estão cada vez mais sofisticados e preparados, inseridos em todas as camadas da sociedade, fazendo com que seja necessário que a legislação pondere as suas implicações e efeitos a nível jurídico e ético. Para os países da União Europeia, quanto maior for a capacidade de autonomia dos robôs, menos eles podem ser encarados como meros instrumentos, o que suscita a reflexão sobre se a legislação vigente seria suficiente para solucionar eventuais lides que envolvam o assunto, ou se novos princípios e normas seriam necessários para clarificar a responsabilidade jurídica de várias pessoas no que diz respeito à responsabilidade por atos lesivos e omissões dos robôs. ${ }^{36}$

Pires e Silva identificam diferentes áreas em que o tema de responsabilidade pelos atos de IA precisa ser discutido e delimitado. A responsabilidade por alguma anomalia em um produto seria do fabricante, enquanto a responsabilidade por um comportamento que provoque prejuízos seria da pessoa que está utilizando o produto. Os problemas no tema da responsabilização de atos de IA se estendem também para a demarcação da responsabilidade contratual e extracontratual, para os casos em que houver defeito no produto, para a questão das responsabilidades individuais, para a análise sobre a responsabilidade social, para a responsabilidade de desenvolver produtos que sejam seguros e adequados à sua finalidade, para as questões relacionadas à privacidade como o acesso a dados armazenados, para a responsabilidade por danos patrimoniais, para a responsabilidade pela gestão de riscos, entre outras áreas em que a responsabilização precisa ser codificada. ${ }^{37}$

Os autores destacam que uma possível solução jurídica para a complexidade de atribuir responsabilidade pelos danos causados pelos robôs pode ser a criação de um regime de seguros obrigatórios para a robótica, abrangendo todos os potenciais elementos da cadeia de responsabilidade. Para os casos que não estivessem cobertos por seguro, seria criado um fundo de garantia da reparação de danos. Os fundos de indenização poderiam ser configurados de diferentes formas: como um fundo geral para todos os robôs autônomos inteligentes; ou com a criação de um fundo individual para toda e qualquer categoria de robôs, através de uma contribuição que deveria ser paga a título de taxa no momento em que se coloca o robô no mercado; ou até mesmo por intermédio do pagamento de contribuições periódicas durante o

\footnotetext{
${ }^{36}$ UNIÃO EUROPEIA. Resolução 2015/2103 (INL), de 16 de fevereiro de 2017. Contém recomendações à Comissão sobre disposições de Direito Civil sobre Robótica. Disponível em: https://www.europarl.europa.eu/doceo/document/A-8-2017-0005_PT.html\#title2. Acesso em: 29 abr. 2020. ${ }^{37}$ Ibidem.
} 
tempo de vida do robô - se essa fosse a estratégia adotada, um estatuto jurídico específico seria criado para os "robôs a longo prazo".

De outra parte, para os casos em que os robôs tomam decisões autônomas ou interagem por qualquer outro modo com terceiros de forma independente, eventualmente lhes seria atribuída uma "personalidade eletrônica". A ligação entre os robôs e o respectivo fundo de indenização seria feita por um número de registro individual atribuído a cada robô. Esse número permitiria que qualquer pessoa que interagisse com o robô fosse informada da natureza do fundo, dos limites da respetiva responsabilidade em caso de danos patrimoniais, dos nomes e dos cargos dos contribuintes, entre outras informações relevantes. ${ }^{38}$

Para Ferreira $^{39}$, pesquisadora da Faculdade de Direito da Universidade de Coimbra (Portugal), a atribuição de personalidade jurídica aos robôs que operam autonomamente escolhas éticas não é necessária nem útil considerando que a questão principal não é fazer deles titulares autônomos de direitos, mas encontrar uma maneira de responsabilizar eventuais atos lesivos. A autora entende que a análise de quem seria a culpa não é um caminho desejável, o mais adequado seria se questionar se era esperado que o robô atuasse de outra forma, tendo em conta as circunstâncias e o meio em que atuou. Para a autora, a busca por alternativas para resolver as relações de responsabilidade entre humanos e robôs poderia considerar alguns institutos jurídicos como:

a) a exigência de consentimento informado para ser tratado por um robô; b) uma redefinição da responsabilidade do produtor relativamente à disponibilização de atualizações e respetivos deveres de informação; c) uma clara obrigação de updating por parte de quem beneficia do trabalho de robôs autónomos; d) a existência de seguros/fundos de garantia concernentes à utilização de robôs. ${ }^{40}$

O ordenamento jurídico brasileiro ainda não conta com regras específicas para o uso da IA, todavia, há um esforço por parte da doutrina de enquadrar hipoteticamente alguns casos à legislação já existente e analisar a aplicabilidade das normas.

Apenas para exemplificar uma das áreas em que há repercussão da questão da responsabilização pelos atos de sistemas de IA, no âmbito do Direito do Consumidor há autores

\footnotetext{
${ }^{38}$ UNIÃO EUROPEIA. Resolução 2015/2103 (INL), de 16 de fevereiro de 2017. Contém recomendações à Comissão sobre disposições de Direito Civil sobre Robótica. Disponível em: https://www.europarl.europa.eu/doceo/document/A-8-2017-0005_PT.html\#title2. Acesso em: 29 abr. 2020.

${ }^{39}$ FERREIRA, Ana Elisabete. Responsabilidade civil extracontratual por danos causados por robôs autónomos: breves reflexões. Revista Portuguesa de do Dano Corporal, Coimbra, v. 27. Ano 25, p. 39-63, dez. 2016. Disponível em: https://doi.org/10.14195/1647-8630_27_3. Acesso em: 27 abr. 2020. p. 46-52.

${ }^{40}$ FERREIRA, Ana Elisabete. Responsabilidade civil extracontratual por danos causados por robôs autónomos: breves reflexões. Revista Portuguesa de do Dano Corporal, Coimbra, v. 27. Ano 25, p. 39-63, dez. 2016. Disponível em: https://doi.org/10.14195/1647-8630_27_3. Acesso em: 27 abr. 2020. p. 62.
} 
que entendem que o fornecedor de IA poderá ser responsabilizado por situações de defeitos de concepção, produção, e de informação de acordo com o Código de Defesa do Consumidor (CDC). $\mathrm{O}$ artigo $2^{\circ}$ do CDC determina o conceito jurídico de consumidor como sendo "toda pessoa física ou jurídica que adquire ou utiliza produto ou serviço como destinatário final". ${ }^{41}$ Já o artigo $3^{\circ}$ caput e parágrafo primeiro definem o conceito de fornecedor e de produto, conforme segue:

\begin{abstract}
Art. $3^{\circ}$ Fornecedor é toda pessoa física ou jurídica, pública ou privada, nacional ou estrangeira, bem como os entes despersonalizados, que desenvolvem atividade de produção, montagem, criação, construção, transformação, importação, exportação, distribuição ou comercialização de produtos ou prestação de serviços.

$\S 1^{\circ}$ Produto é qualquer bem, móvel ou imóvel, material ou imaterial. ${ }^{42}$
\end{abstract}

Quando pensamos sobre relações de consumo e a comercialização dos produtos dotados da tecnologia de IA, temos que diversos sujeitos poderão se enquadrar no conceito jurídico de fornecedor: os programadores dos sistemas, os fabricantes do hardware e, por vezes, até mesmo os comerciantes também poderão ser considerados fornecedores de sistemas de IA, mesmo não integrando sua cadeia produtiva. Também é possível enquadrar a tecnologia de IA no conceito jurídico de produto, tendo em vista que bens imateriais como softwares e materiais como hardwares podem ser comercializados e, portanto, serem objetos de uma relação de consumo. ${ }^{43}$

Seguindo a análise da matéria à luz do CDC, a Seção II, a partir do artigo 12, estabelece as regras de responsabilidade pelo fato do produto e do serviço, que ocorre quando danos são causados por defeito do produto ou serviço. Na hipótese da existência dos elementos que configurem fato do produto ou do serviço, a responsabilização dos sujeitos envolvidos em seu fornecimento será objetiva, o que significa que independerá da existência de culpa. Todavia, fato é que não há produto ou serviço totalmente seguro e o Direito deve atuar apenas quando a insegurança excede aos níveis considerados normais e previsíveis pela coletividade de consumidores. Sendo assim, não são todas as decisões adotadas pelas tecnologias de IA e que ocasionem danos a consumidores que poderão resultar em responsabilização dos seus fornecedores. Eventuais decisões da IA que não foram programadas devem ser observadas dentro de um patamar de previsibilidade, normalidade e razoabilidade das ações que deveriam

\footnotetext{
${ }^{41}$ BRASIL. Lei $n$. 8.078, de 11 de setembro de 1990. Disponível em: http://www.planalto.gov.br/ccivil_03/leis/18078.htm. Acesso em: 12 ago. 2020.

42 Ibidem.

${ }^{43}$ FERREIRA, Diogo Ramos. A responsabilidade civil dos fornecedores de inteligência artificial. São Paulo: Thomson Reuters, 2019.
} 
ou poderiam ser realizadas, conforme a finalidade para a qual tais sistemas foram criados. $\mathrm{O}$ que estiver fora do padrão esperado, pode ser responsabilizado. ${ }^{44}$

Outra particularidade é dever de informação, que obriga que o fornecedor comunique claramente os riscos inerentes aos sistemas de IA. Assim, os fornecedores poderão ser responsabilizados caso não proporcionem, adequada e ostensivamente as informações a respeito das peculiaridades da IA. ${ }^{45}$

Em que pese o esforço da doutrina em tentar buscar respostas jurídicas para a matéria, atualmente não há no Brasil previsão legal que cubra as situações em que haja erro por parte das tecnologias autônomas de IA que são utilizadas na área médica, e essa segue sendo uma carência que impede um uso mais abrangente dessa ferramenta em diagnósticos, tratamentos e outras situações da rotina na área da saúde. Outra questão que legalmente permanece em aberto é a proteção dos conjuntos de dados que são coletados, armazenados e utilizados para alimentar os sistemas que operam com a IA gerando um desconforto ainda maior em matéria de segurança jurídica.

Áreas como o direito civil, penal e administrativo, por exemplo, também são bastante impactadas com a questão em análise e demandariam um exame aprofundado da matéria. Entretanto, por questões de limitação de extensão do presente trabalho, deixaremos de traçar considerações específicas sobre cada uma das searas.

\section{CONCLUSÃO}

Essa pesquisa não teve a pretensão de apresentar um estudo semântico aprofundado, mas apenas anotações para a abertura de debates sobre a matéria que relaciona a autonomia nas ações de sistemas que operam por intermédio da Inteligência Artificial (IA) e suas implicações legais, principalmente nos atos ligados a atividades da medicina. Portanto sem a ambição de fazer prescrições ou apontar soluções, é possível chegar a algumas conclusões.

Primeiramente, acreditamos que é provável que o homem não será totalmente substituído pela IA, pois, apesar de deter o conhecimento de como executar certa tarefa - por vezes apresentando resultados ágeis que os de um ser humano -, robôs e softwares jamais poderão

\footnotetext{
${ }^{44}$ FERREIRA, Diogo Ramos. A responsabilidade civil dos fornecedores de inteligência artificial. São Paulo: Thomson Reuters, 2019.

${ }^{45}$ Ibidem.
} 
oferecer o suporte emocional e psicológico que a interação entre seres humanos pode proporcionar.

Ademais, uma eventual autonomia concedida a esses sistemas pode desencadear ações imprevisíveis tendo em vista as características das técnicas e métodos de machine learning e deep learning, conforme visto anteriormente. O problema jurídico proposto se projeta quando essas ações autônomas geram algum tipo de dano, principalmente se idealizados na área médica, incitando a questão sobre como seria uma eventual responsabilização jurídica por esses atos.

A priori, uma eventual imputação da responsabilidade legal estaria associada sempre a uma pessoa física ou jurídica, atrelada à IA. De qualquer forma, para que sejam aplicáveis, as potenciais abordagens para a solução do problema da responsabilização devem se manter de acordo com os requisitos de legalidade dos ordenamentos jurídicos.

O uso dos robôs na medicina continua abrindo novas perspectivas na execução de cirurgias de alta precisão, de procedimentos com movimentos repetitivos e têm potencial para melhorar os resultados da reabilitação e prestar um apoio logístico altamente eficaz nos hospitais. Entretanto, o crescimento no domínio da robótica e da IA automatizará um número significativo de postos de trabalho, o que pressupõe uma avaliação dos riscos e o planejamento de medidas destinadas a assegurar que os aspetos relacionados com a sociedade, o ambiente, a ética, a responsabilidade e o ensino sejam devidamente tidos em conta.

No Brasil, até o presente momento em 2020, os sistemas de IA não podem suportar autonomamente qualquer responsabilidade porque o ordenamento jurídico brasileiro não dispõe de normas que viabilizem a solução do problema nesse sentido. No mesmo sentido, a revisão bibliográfica do presente trabalho não encontrou previsão legal para eventuais erros de atos autônomos de IA quando relacionados à área médica.

Assim, a discussão sobre a responsabilização dos atos de IA na área médica tem um papel muito importante para a sociedade, pois ao mesmo tempo que a IA na medicina pode trazer avanços que prolongam a vida e promovem o bem estar das pessoas, ações autônomas de IA carecem de uma segurança jurídica que viabilize sua aplicabilidade plena.

Um ponto essencial é a possibilidade de usar sistemas que possam ter seu funcionamento rastreado, como forma de validação da ação da IA e, sendo assim, médicos e outros profissionais da saúde não devem ser reduzidos a meros executores de resultados advindos da análise através da IA. Assim, a supervisão de um profissional da área da saúde é imprescindível 
e, se houver uma razão profissional fundamentada suficiente para acreditar que o modelo está errado ou a ação for suspeita ou incoerente, a decisão deverá ser substituída.

A utilização de IA na medicina envolve riscos que devem ser cuidadosamente ponderados face aos benefícios que possam proporcionar. É de salientar que a robótica pode instigar um elevado nível de incerteza quanto às responsabilidades, todavia, diante do cenário em que um robô pode tomar decisões autônomas, o certo é que as normas existentes não são suficientes para solucionar problemas de responsabilidade jurídica pelos danos causados por um robô, uma vez que na maioria dos casos não seria possível identificar a parte responsável para prestar a indenização e para exigir a reparação dos danos causados.

Por fim, a pesquisa nos permitiu identificar que além da lacuna legal, diretrizes concretas para a análise das consequências do uso de modelos baseados na IA também são raras na literatura nacional e internacional, deixando à deriva questões cruciais como ética e privacidade de dados.

\section{REFERÊNCIAS}

AHMED, Zeeshan et al. Artificial intelligence with multi-functional machine learning platform development for better healthcare and precision medicine. Database: The journal of Biological Database and Curation, Oxford, v. 2020, p. 1-35, 2020. Disponível em: https://academic.oup.com/database/article/doi/10.1093/database/baaa010/5809229. Acesso em: 05 mai. 2020.

ANDERSON, Michael; ANDERSON, Susan. Robot be good. Scientific American, 2010. Disponível em: https://www.scientificamerican.com/article/robot-be-good/. Acesso em: 20 mai. 2020. p. 75-76.

ASARO, Peter M. A Body to kick, but still no soul to damn: legal perspectives on Robotics. In: LIN, Patrick; ABNEY, Keith; BEKEY, George A. Robot Ethics: the ethical and social implications of Robotics. Massachusetts: The MIT Press, 2012.

BLUEDOT. Our leadership on COVID-19. Disponível em: https://bluedot.global. Acesso em: 06 ago. 2020.

BRASIL. Lei $n$. 12.842, de 10 de julho de 2013. Disponível em: http://www.planalto.gov.br/ccivil_03/_ato2011-2014/2013/lei/l12842.htm. Acesso em: 12 mai. 2020 .

BRASIL. Lei n. 13.709, de 14 de agosto de 2018. Disponível em: http://www.planalto.gov.br/ccivil_03/_ato2015-2018/2018/lei/L13709.htm. Acesso em: 12 mai. 2020. 
BRASIL. Lei n. 8.078, de 11 de setembro de 1990. Disponível em: http://www.planalto.gov.br/ccivil_03/leis/18078.htm. Acesso em: 12 ago. 2020.

CFM. Conselho Federal de Medicina. Despacho CFM n. 319/2019. Disponível em: https://sistemas.cfm.org.br/normas/visualizar/despachos/BR/2019/319. Acesso em: 12 mai. 2020.

DEMARTINI, Felipe. Inteligência artificial emitiu aviso sobre coronavírus em dezembro. Canaltech. Disponível em: https://canaltech.com.br/saude/inteligencia-artificial-emitiu-avisosobre-coronavirus-em-dezembro-159607/. Acesso em: 06 ago. 2020.

DONEDA, Danielo Cesar et al. Considerações iniciais sobre inteligência artificial, ética e autonomia pessoal. Revista de Ciências Jurídicas, Fortaleza, v. 23, n. 4, p. 1-17, out./dez. 2018. Disponível em: https://periodicos.unifor.br/rpen/article/view/8257. Acesso em: 02 set. 2019.

FERREIRA, Ana Elisabete. Responsabilidade civil extracontratual por danos causados por robôs autónomos: breves reflexões. Revista Portuguesa do Dano Corporal, Coimbra, v. 27. Ano 25, p. 39-63, dez. 2016. DOI: https://doi.org/10.14195/1647-8630_27_3.

FERREIRA, Diogo Ramos. A responsabilidade civil dos fornecedores de inteligência artificial. São Paulo: Thomson Reuters, 2019.

HACKER, P. et al. Explainable AI under contract and tort law: legal incentives and technical challenges. Artificial Intelligence and Law, Berlin, v. 28, p. 415-439, 2020. Disponível em: https://link.springer.com/article/10.1007/s10506-020-09260-6. Acesso em: 27 abr. 2020.

KARNOW, Curtis E. A. The application of traditional tort theory to embodied machine intelligence. In: CALO, Ryan; FROOMKIN, A. Michael; KERR, Ian. Robot law. Cheltenham, United Kingdom: Edward Elgar Publishing, 2015. Disponível em: https://works.bepress.com/curtis_karnow/9/. Acesso em: 13 ago. 2020.

KNIGHT, Will. The dark secret at the heart of AI: no one really knows how the most advanced algorithms do what they do - that could be a problem. Technology Review, 2017. Disponível em: https://www.technologyreview.com/2017/04/11/5113/the-dark-secret-at-the-heart-of-ai/. Acesso em: 29 abr. 2020.

LIMA, Gercina Ângela Borém. Interfaces entre a ciência da informação e a ciência cognitiva. Ciência da Informação, Brasília, v. 32, n. 1, p. 77-87, jan./abr. 2003. Disponível em: https://www.scielo.br/scielo.php?script=sci_arttext\&pid=S0100-

19652003000100008\&lng=en\&nrm=iso. Acesso em: 04 ago. 2020.

LOBO, Luiz Carlos. Inteligência artificial, o futuro da medicina e a educação médica. Revista Brasileira de Educação Médica, Brasília, v. 42, n. 3, p. 3-8, set. 2018. Disponível em: http://www.scielo.br/scielo.php?script=sci_arttext\&pid=S0100-

55022018000300003\&lng=en\&nrm=iso. Acesso em: 13 abr. 2020.

MONARD, Maria Carolina; BARANAUSKAS, José Augusto. Aplicações de inteligência artificial: uma visão geral. In: CONGRESSO DE LÓGICA APLICADA À TECNOLOGIA 
(LAPTEC), 1., 2000, São Paulo. Anais... São Paulo: USP, 2000. Disponível em: http://dcm.ffclrp.usp.br/ augusto/publications/2000-laptec.pdf. Acesso em: 13 ago. 2020.

PIRES, Thatiane Cristina Fontão; SILVA, Rafael Peteffi da. A responsabilidade civil pelos atos autônomos da inteligência artificial: notas iniciais sobre a Resolução do Parlamento Europeu. Revista Brasileira de Políticas Públicas, Brasília, v. 7, n. 3, p. 238-254, dez. 2017. Disponível em: https://www.publicacoesacademicas.uniceub.br/RBPP/article/view/4951/3643. Acesso em: 16 abr. 2020.

SALATHÉ, Marcel. Digital epidemiology: what is it, and where is it going? Life Sciences, Society and Policy, New York, v. 14, n. 1, p. 1-5, 2018. Disponível em: https://lsspjournal.biomedcentral.com/articles/10.1186/s40504-017-0065-7. Acesso em: 12 mai. 2020.

SOUZA, Cesar Alexandre de. PAULI, Sergi. A nova era da inteligência artificial e o futuro do trabalho. Revista Fonte: Tecnologia da Informação na Gestão Pública, Minas Gerais, Ano 14, n. 17, p. 77-83, jul. 2017. Disponível em: https://www.prodemge.gov.br/revistafonte/Publication/19-Computacao-cognitiva-e-a-humanizacao-das-maquinas. Acesso em: 04 ago. 2020.

TOPOL, Eric J. High-performance medicine: the convergence of human and artificial intelligence. Nature Medicine, China, v. 25, p. 44-56, jan. 2019. DOI: https://doi.org/10.1038/s41591-018-0300-7.

UNIÃO EUROPEIA. Resolução 2015/2103 (INL), de 16 de fevereiro de 2017. Contém recomendações à Comissão sobre disposições de Direito Civil sobre Robótica. Disponível em: https://www.europarl.europa.eu/doceo/document/A-8-2017-0005_PT.html\#title2. Acesso em: 29 abr. 2020.

WHO. World Health Organization. Global health ethics: big data and artificial intelligence. Disponível em: https://www.who.int/ethics/topics/big-data-artificial-intelligence/en/. Acesso em: 12 mai. 2020.

ZIVIANI, Nivio. Diálogo. Revista Fonte: Tecnologia da Informação na Gestão Pública, Minas Gerais, Ano 14, n. 17, p. 6-12, jul. 2017. Disponível em: https://www.prodemge.gov.br/revistafonte/Publication/19-Computacao-cognitiva-e-a-humanizacao-das-maquinas. Acesso em: 04 ago. 2020.

ZIVIANI, Nivio. Projeto de Algoritmos com Implementações em Pascal e C. São Paulo: Pioneira, 1999.

\section{DADOS DA PUBLICAÇÃO}

Categoria: artigo submetido ao double-blind review.

Recebido em: 17/09/2020.

Aceito em: 31/05/2021. 